\title{
12(S)-hydroxyheptadeca-5Z,8E,10E-trienoic acid (12-HHT) induces cell growth and improves barrier function through BLT2 interaction in intestinal epithelial Caco-2 cell cultures
}

\author{
C.E. Storniolo ${ }^{\text {a }}$, M. Pequera ${ }^{\text {a }}$, F. Company ${ }^{a}$, J.J. Moreno ${ }^{\text {a,b, }}$ \\ ${ }^{\text {a }}$ Department of Nutrition, Food Sciences and Gastronomy, Institute of Nutrition and Food Safety, University of Barcelona, Campus Torribera, Barcelona, Spain \\ b CIBEROBN Fisiopatologia de la Obesidad y Nutrición, Instituto de Salud Carlos III, Madrid, Spain
}

\section{A R T I C L E I N F O}

\section{Keywords:}

Eicosanoid

Colorectal cancer

Intestinal inflammation

Cell signalling

\begin{abstract}
A B S T R A C T
12(S)-hydroxyheptadeca-5Z,8E,10E-trienoic acid (12-HHT) is an unusual product of the cyclooxygenase pathway that is an endogenous ligand of the low-affinity receptor for leukotriene $4\left(\mathrm{LTB}_{4}\right)$, BLT2. Recent findings suggested that BLT2 possibly plays an important role in the healing of intestinal lesions and the regulation of barrier function. Here, we studied the role of 12-HHT on intestinal epithelial cell growth and the paracellular permeability of intestinal epithelium using Caco-2 cell cultures as experimental model. Our results demonstrated that 12-HHT stimulates intestinal epithelial Caco-2 cell growth through 12-HHT-BLT2-p38-PKC axis and improves paracellular permeability in differentiated Caco-2 cell cultures through the regulation of tight junction elements such as myosin light chain phosphorylation through 12-HHT-BLT2-p38-PKC-MYPT1 axis. Thus, 12-HHT-BLT2 interaction can be involved in intestinal epithelial cell growth and consequently in the epithelium regeneration/repair processes, together with an interesting improvement on the paracellular permeability. These effects appoint that 12-HHT/BLT2 axis may be a suitable strategy for treating wound healing epithelium and barrierdisrupted intestinal processes.
\end{abstract}

\section{Introduction}

12(S)-hydroxyheptadeca-5Z,8E,10E-trienoic acid (12-HHT) is an unusual product of the cyclooxygenase (COX) pathway and one of the mainly arachidonic acid (AA) metabolites of the human platelets [1]. It is biosynthesized by thromboxane synthase from prostaglandin $\mathrm{H}_{2}$ $\left(\mathrm{PGH}_{2}\right)$ concurrently with thromboxane $\mathrm{A}_{2}\left(\mathrm{TXA}_{2}\right)$ [2]. This enzyme uses two molecules of $\mathrm{PGH}_{2}$ and catalyzes the isomerization of one molecule of $\mathrm{PGH}_{2}$ to 12-HHT and malondialdehyde [2]. Finally, 12-HHT is metabolized to 12-oxo-heptadecatrienoic acid by 15-hydroxyprostaglandin dehydrogenase [3]. Although 12-HHT was identified several decades ago, it was considered merely as a byproduct of $\mathrm{TXA}_{2}$ production during hemostatic processes. However, in 2008, Okuno and coworkers demonstrated that 12-HHT is an endogenous ligand of the low-affinity receptor for leukotriene $4\left(\mathrm{LTB}_{4}\right)$, BLT2 [4]. Although the biological role of the BLT1-LTB 4 signaling axis has been investigated in detail, the physiological and pathological roles of BLT2 remain largely unknown. BLT2 receptor has a broad substrate specificity for several eicosanoids such as $\mathrm{LTB}_{4}$, 12-hydroxyeicosatetraenoic acid (12-HETE), 15-HETE and 12-HHT. BLT2 is expressed in epithelial cells such as intestinal epithelial cells $[5,6]$ in contrast to a high-affinity LTB $_{4}$ receptor (BLT1) circumscribed to leukocytes.

12-HHT is synthesized by different cells such as alveolar macrophages [7], cultured keratinocytes [8], mammary adenocarcinoma tumor cells [9], and tissues such as colon [10].

Eicosanoids are involved in the gut physiology/pathophysiology through the modulation of cell growth/cell differentiation/apoptosis and the regulation of paracellular permeability of the intestinal epithelium [11]. BLT2 is considered a pivotal element in the intestinal homeostasis [10]. Thus, Iizuka et al. [10] suggested the involvement of a BLT2 axis as a regulator of acute colonic injury, and suggested that 12HHT could mediate an anti-inflammatory response via its possible receptor, BLT2, in dextran sodium sulfate induced inflammatory colitis, but little is known about its other physiological functions. In this way, we reported the involvement of 12-HETE-BLT2 [12] and 13-(R)hydroxyoctadecanoid acid (13-HODE)-BLT2 [13] interactions in the

\footnotetext{
* Corresponding author at: Department of Nutrition, Food Sciences and Gastronomy, Faculty of Pharmacy and Food Sciences, University of Barcelona, Campus Torribera, Avda. Prat de la Riba 171, 08921 Santa Coloma de Gramenet, Barcelona, Spain.

E-mail address: jjmoreno@ub.edu (J.J. Moreno).
} 

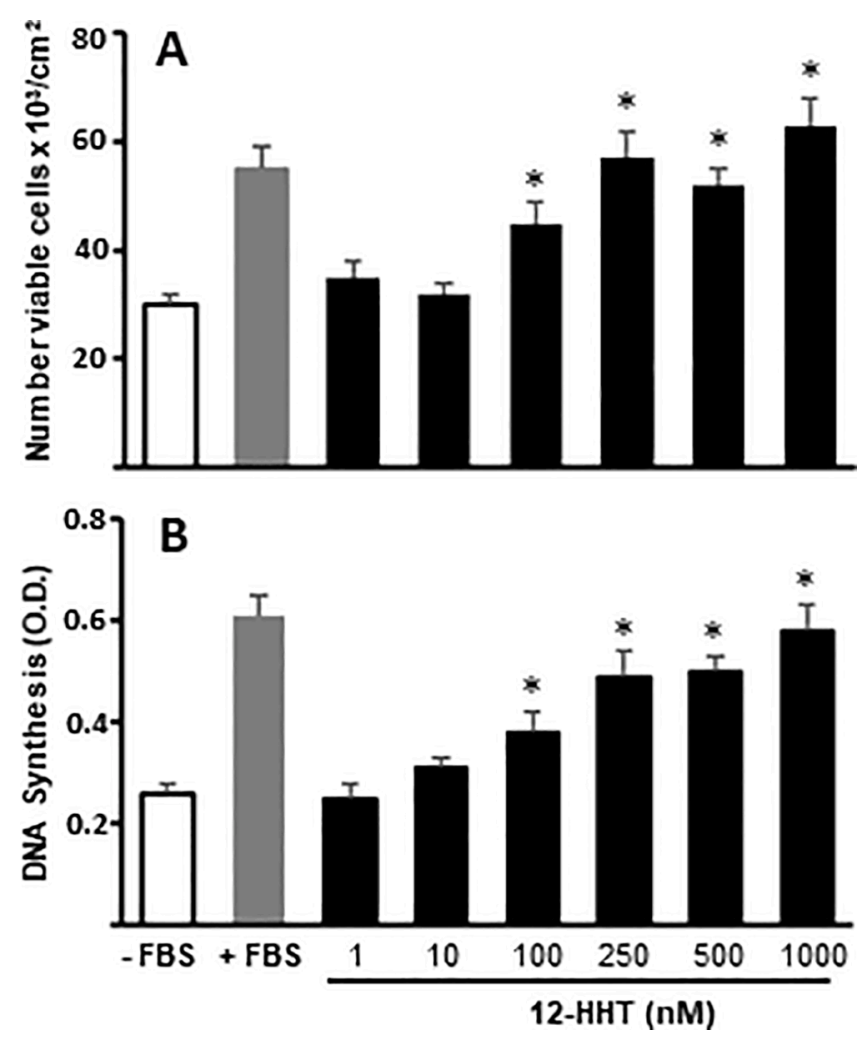

Fig. 1. Effect of 12-HHT on Caco-2 cell growth. Pre-confluent Caco-2 cell cultures were incubated for $48 \mathrm{~h}$ with 12-HHT (1-1000 nM) in the absence of growth factors (FBS). Caco-2 cells were counted (A), and DNA synthesis was measured (B). Results are expressed as means \pm SEM of 4 determinations performed in triplicate. ${ }^{*} \mathrm{P} \leq 0.05$ vs. Caco- 2 cell cultured in the absence of FBS (white bar). Cells cultured in presence of 10\% FBS (gray bar) were used as positive control of cell proliferation.

control of intestinal epithelial Caco-2 proliferation.

Considering all together, the aim of this work was studied the hypothetical role of 12-HHT on intestinal epithelial cell growth and the paracellular permeability of intestinal epithelium using Caco-2 cell cultures as experimental model. In this report, we show that 12-HHT stimulates intestinal epithelial cell growth using undifferentiated Caco- 2 cell cultures and improves paracellular permeability in complete differentiated Caco- 2 cell cultures.

\section{Materials and methods}

\subsection{Materials}

12-HHT, prostaglandin $\mathrm{E}_{2}\left(\mathrm{PGE}_{2}\right)$, MK571, LY171883, SC19220, U73122 and U-75302 were purchased from Cayman Chemical (Ann Arbor, MI, USA). Fluorescein isothiocyanate-dextran (FD-4, average mol wt 3000-5000), ketoprofen, pertussis toxin, KT5720, PD98059, Go6983, SB203580, Y27632, ethidium bromide and acridine orange were purchased from Sigma-Aldrich (St. Louis, MO, USA). LY 255,283 was from Tocris Biosc. (Bristol, UK). AH 23,838 was kindly supplied by Glaxo-Wellcome (Stevenage, UK). Dulbecco's Modified Eagle's Medium (DMEM), fetal bovine serum (FBS), trypsin, penicillin, streptomycin, and cell culture supplementary products were supplied by GIBCO (Paisley, UK). siRNA BLT2 (s195305) was supplied by Thermo Fisher Scientific (Waltham, MA, USA). Caco-2 cell cultures were transfected with siRNA BLT2 during $48 \mathrm{~h}$ using Lipofectamine 2000 (Invitrogen, Carlsbad, CA, USA).

\subsection{Cell culture and cell growth assay}

Caco- 2 cells derived from a moderately well-differentiated primary colon adenocarcinoma were provided by American Type Culture Collection (HTB-37, Manassas, VA, USA). The cells were routinely grown in 75 or $150 \mathrm{~cm}^{2}$ plastic flasks at a density of $10^{4} \mathrm{cells} / \mathrm{cm}^{2}$ and cultured in DMEM supplemented with $4.5 \mathrm{~g} / 1$ D-glucose, 1\% (v/v) nonessential amino acids, $2 \mathrm{mM}$ L-glutamine, $10 \%(\mathrm{v} / \mathrm{v})$ heatinactivated FBS, $100 \mathrm{U} / \mathrm{ml}$ penicillin, and $100 \mu \mathrm{g} / \mathrm{ml}$ streptomycin at $37{ }^{\circ} \mathrm{C}$ in a modified atmosphere of $5 \% \mathrm{CO}_{2}$ in air. The growth medium was replaced twice per week and the day before the experiment.

Cell growth/DNA synthesis experiments were performed in preconfluent cultures ( $\leq 80 \%$ confluency) and consequently, in nondifferentiated Caco-2 cells. Cell differentiation started when they reached the confluence and was completed after 2 weeks postconfluence, a process which was previously described [14].

To perform the cell growth assay, cells were harvested with trypsin/ EDTA and passed to $12 \mathrm{~mm}$ plastic clusters at a density of $10^{4}$ cells $/ \mathrm{cm}^{2}$. After 4 days in culture, pre-confluent cell cultures $\left(3-4 \times 10^{4}\right.$ cells $\left./ \mathrm{cm}^{2}\right)$ were replaced with FBS-free culture medium before to be incubated with treatments for a period of $48 \mathrm{~h}$. Finally, cells were washed, trypsinized, and counted with a microscope using ethidium bromide/acridine orange staining to measure viable cells.

\subsection{Analysis of DNA synthesis}

DNA synthesis in Caco-2 cells was assessed by a colorimetric immunoassay based on the measurement of BrdU incorporation during DNA synthesis (Cell proliferation ELISA, BrdU Kit, from Roche, Basel, Switzerland). Caco-2 cells were cultured at 1000-1500 cell/well in 96 well plates for $96 \mathrm{~h}$ in DMEM supplemented with 10\% FBS. Then, cells were incubated for $48 \mathrm{~h}$ in the presence of compounds. Thereafter, cells were treated following the manufacturer instructions. Absorbance was measured at $450 \mathrm{~nm}$ in a plate reader (TECAN, Sunrise, Grödig, Austria).

\subsection{Measurement of the cell signaling pathways activated by eicosanoids}

Cells were seeded in $60 \mathrm{~mm}$ plastic clusters $\left(10^{4}\right.$ cells $\left./ \mathrm{cm}^{2}\right)$ and, after 4 days, the cultures were incubated with the treatments ( 5 or $15 \mathrm{~min}$ ). To measure the kinase activation with total cellular lysates, Caco- 2 cells were lysed using a denaturing cell lysis buffer containing $6 \mathrm{M}$ urea and protease (leupeptin $2 \mu \mathrm{g} / \mathrm{ml}$, pepstatin $10 \mu \mathrm{M}$, aprotinin $3 \mu \mathrm{g} / \mathrm{ml}$ ) and phosphatase (NaF $5 \mathrm{mM}, \mathrm{Na}_{4} \mathrm{P}_{2} \mathrm{O}_{7} 2 \mathrm{mM}, \mathrm{Na}_{3} \mathrm{VO}_{4} 1 \mathrm{mM}$ ) inhibitors (Sigma-Aldrich). Proteins in cell samples were measured using Bio-Rad protocol with Coomassie brilliant blue G-250 (Bio-Rad, Hercules, CA, USA) as a dye reagent. The resulting solutions containing 80-100 $\mu \mathrm{g}$ of proteins were then added to kinase ELISA plate and the assay was performed following the manufacturer's recommendations (Symansis, Auckland, New Zealand). Finally, optical density was measured at 450 $\mathrm{nm}$. Thus, we studied the effect of eicosanoids on the phosphorylation of AKT1 (pS473), AKT2 (pS474), ERK1/2 (pT202/Y204; pT185/Y187), GSK3 $\beta$ (pS9), p38 $\alpha$ (pT180/Y182), CREB (pS133) and on the dephosphorylation of $\beta$-catenin (DP S33/S37/S41).

\subsection{Western blot}

Cells grown in plastic dishes were washed twice with ice-cold PBS, scrapped of into PBS, and pelleted. Proteins in cell samples were measured as above mentioned. The pellets were then sonicated in lysis buffer containing $2 \mathrm{~m} \mathrm{M}$ sodium EDTA, $20 \mu \mathrm{g} / \mathrm{mL}$ aprotinin, $20 \mu \mathrm{g} / \mathrm{mL}$ leupeptin, $20 \mu \mathrm{g} / \mathrm{mL}$ phenylmethylsulphonyl fluoride, $200 \mu \mathrm{g} / \mathrm{mL}$ diethyldithiocarbamic acid, $50 \mathrm{mM}$ Tris- $\mathrm{HCl}, 150 \mathrm{mM} \mathrm{NaCl}, 0.5 \%$ Igepal CA-630 and $1 \mathrm{mM}$ dithiothreitol (Sigma-Aldrich). After lysis $30 \mu \mathrm{g}$ of protein (determined by BCA protein assay kit, ThermoFisher Scientific) from cell lysate was mixed with buffer containing $0.5 \mathrm{M}$ Tris- $\mathrm{HCl}, 10 \%$ glycerol, 10\% SDS, $2 \%$ mercaptoethanol and $0.5 \%$ bluebromopherol 


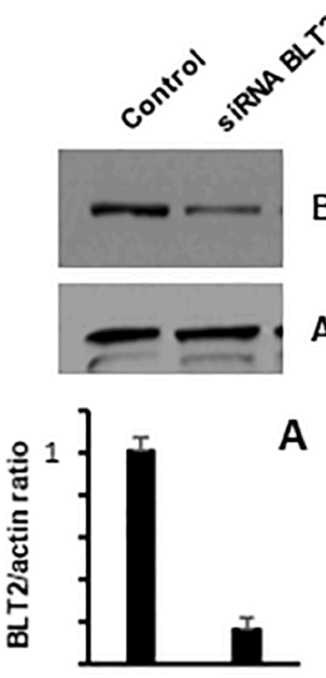

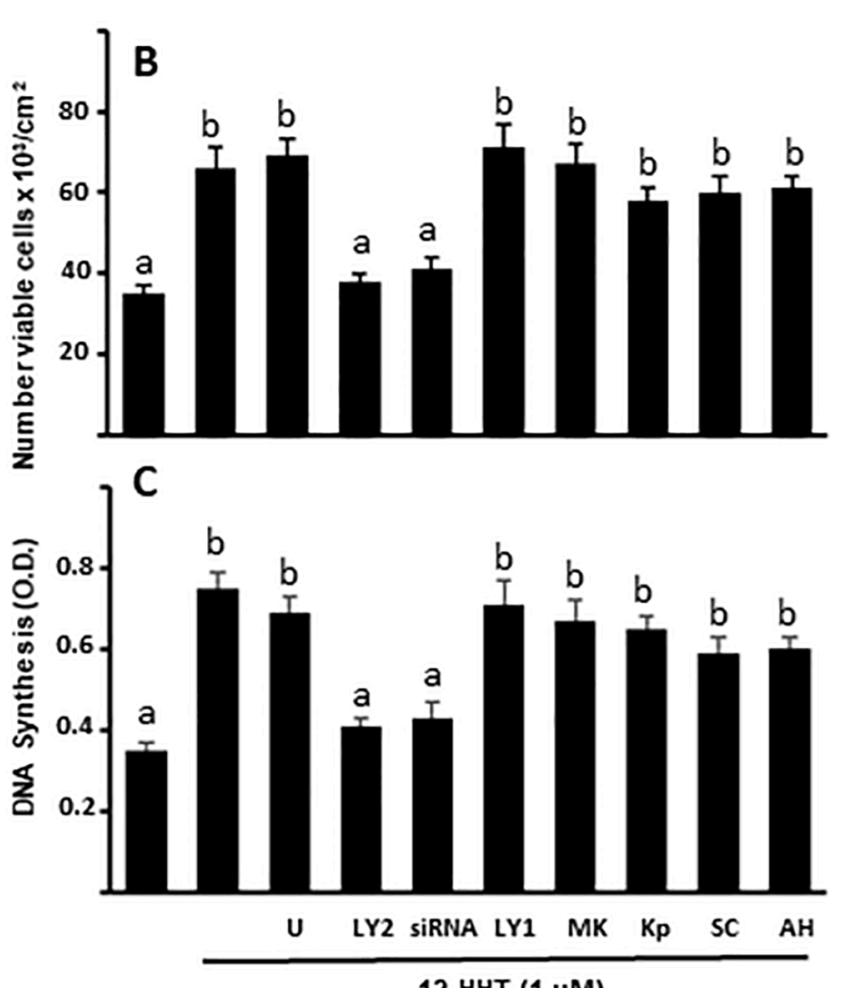

12-HHT (1 $\mu \mathrm{M})$
Fig. 2. Role of eicosanoid receptors on cell growth and DNA synthesis induced by 12HHT in pre-confluent Caco-2 cell cultures. (A) BLT2 expression in Caco- 2 cell cultures in absence/presence of siRNA BLT2. Cells were incubated for $48 \mathrm{~h}$ in presence of U-75302 (U, $5 \mu \mathrm{M})$, LY255283 (LY2, $25 \mu \mathrm{M})$, siRNA BLT2 (siRNA, 100 nM), LY171883 (LY1, 25 $\mu \mathrm{M})$, MK571 (MK, $10 \mu \mathrm{M})$, ketoprofen (Kp, 5 $\mu \mathrm{M})$, SC19220 (SC, $60 \mathrm{nM}$ ) or AH23848 (AH, $20 \mathrm{nM})$ and 12-HHT $(1 \mu \mathrm{M})$. Cells were then counted (B), and DNA synthesis was measured (C). Results are expressed as means \pm SEM of 4-6 determinations performed in triplicate. Values that do not share a common letter $(\mathrm{a}-\mathrm{b})$ were significantly different $(\mathrm{p}<0.05)$.
Table 1

Effects of 12-HHT on cell signalling pathways involved in cell growth.

\begin{tabular}{lll}
\hline Pathway & Control & 12-HHT \\
\hline AKT1 & $0.16 \pm 0.03$ & $0.15 \pm 0.03$ \\
AKT2 & $0.18 \pm 0.02$ & $0.14 \pm 0.03$ \\
P38 $\alpha$ & $0.29 \pm 0.04$ & $0.67 \pm 0.12^{*}$ \\
GSK $\beta$ & $0.19 \pm 0.04$ & $0.26 \pm 0.08$ \\
CREB & $0.21 \pm 0.05$ & $0.28 \pm 0.09$ \\
ERK1/2 & $0.27 \pm 0.03$ & $0.31 \pm 0.08$ \\
\hline
\end{tabular}

Caco- 2 cells were incubated with 12 -HHT (1000 nM) for 5 or $15 \mathrm{~min}$, cells were then collected and phosphorylated AKT1, AKT2, p38 $\alpha$, GSK $\beta$, CREB, and ERK 1/ 2 were measured as described in the Material and Methods section and expressed as optical density $(450 \mathrm{~nm})$. Data are expressed as means \pm SEM of two to four experiments performed in triplicate. ${ }^{*} \mathrm{P}<0.05$ vs. Control (Caco-2 cell cultures in the absence of FBS).

(Sigma-Aldrich) and heated at $100^{\circ} \mathrm{C}$ for $5 \mathrm{~min}$. Samples were separated by $12 \%$ SDS-PAGE gel and blotted for $2 \mathrm{~h}$ at voltage of $100 \mathrm{~V}$ and constant amperage of $400 \mathrm{~mA}$ onto a nitrocellulose membrane (Trans-Blot, $0.45 \mu \mathrm{m}$ pore size, Bio-Rad) using a MiniproteanII system (Bio-Rad). A prestained SDS-PAGE protein standard (Bio-Rad) was used as molecular weight marker to check transfer efficiency. Membranes were blocked with $5 \%$ non-fat milk power in Tris-buffered saline (TBS) $0.1 \%$ Tween20 (TBS-T20) for $1 \mathrm{~h}$. Rabbit polyclonal antiserum directed against myosin light chain 2 (MLC), p-MLC, myosin phosphatase target subunit 1 (MYPT1) and p-MYPT1 (Cell Signaling Technology, Danvers, MA, USA) and BLT2 (Cayman Chem, Co., MI, USA) were applied at a dilution of 1:1000 for $1 \mathrm{~h}$. Monoclonal antibody against phosphorylated p38 MAPK (Sigma-Aldrich) were incubated in a 1:2000 dilution for $1 \mathrm{~h}$. Blots were washed several times with TBS-T20 and incubated with goat antirabbit antibody at a 1:100,000 dilution for $1 \mathrm{~h}$. Antibody binding was visualized by an enhanced chemical luminescence technique using Supersignal West Femto Maximun Sensitivity Substrate (ThermoFisher Scientific) and KodakX-OMAT film (Rochester, NY, USA).

\subsection{Paracellular permeability assays}

Cells grown to $\sim 80 \%$ confluence were trypsinized and subcultured at a density of $4 \times 10^{5}$ cells $/ \mathrm{cm}^{2}$ on polycarbonate filters with a pore size of $0.4 \mu \mathrm{m}$ (Transwells; 12-mmdiameter). The medium was replaced every 3 days and on the day before the experiment. Experiments were performed in cultures 19-21 days after seeding when cells were completely differentiated [14].

Paracellular permeability (PP), ion or large molecule pass through tight junctions, was assayed using transepithelial electrical resistance (TER) and transepithelial FD-4 fluxes determinations. TER is the measurement of electrical resistance across a cellular monolayer, and FD4 flux from apical to basolateral chamber is related to the tight junction state. Both assays assess the barrier function of epithelial cells on a porous support. After $2 \mathrm{~h}$ incubation with 12-HHT in the apical and basolateral compartments, TER was determined at $37^{\circ} \mathrm{C}$ using a Millicell-ERS voltammeter (Millipore, Bedford, MA, USA). The findings were expressed as $\Omega \mathrm{cm}^{2}$ monolayer surface area. The resistance of the supporting membrane was subtracted from all readings before calculations. After TER determination, $1 \mathrm{mg} / \mathrm{mL}$ of FD- 4 was added to the apical compartment and after incubation period $\left(1 \mathrm{~h}\right.$ at $\left.37^{\circ} \mathrm{C}\right)$, the basolateral medium was removed and fluorescence was determined in a Fluorostar Optima (BMG Labtech, Ortenberg, Germany) at excitation and emission wavelengths of $485 \mathrm{~nm}$ and $544 \mathrm{~nm}$, respectively.

\subsection{Statistics}

Results are expressed as mean \pm SEM. All data were compared by one-way ANOVA and Student's $t$-test using SPSS software (SPSS Inc., Chicago, IL). P $<0.05$ was considered to denote significance.

\section{Results}

Our results showed that 12-HHT (100-1000 nM) significantly 


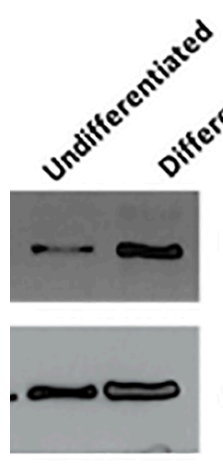

BLT2

Actin
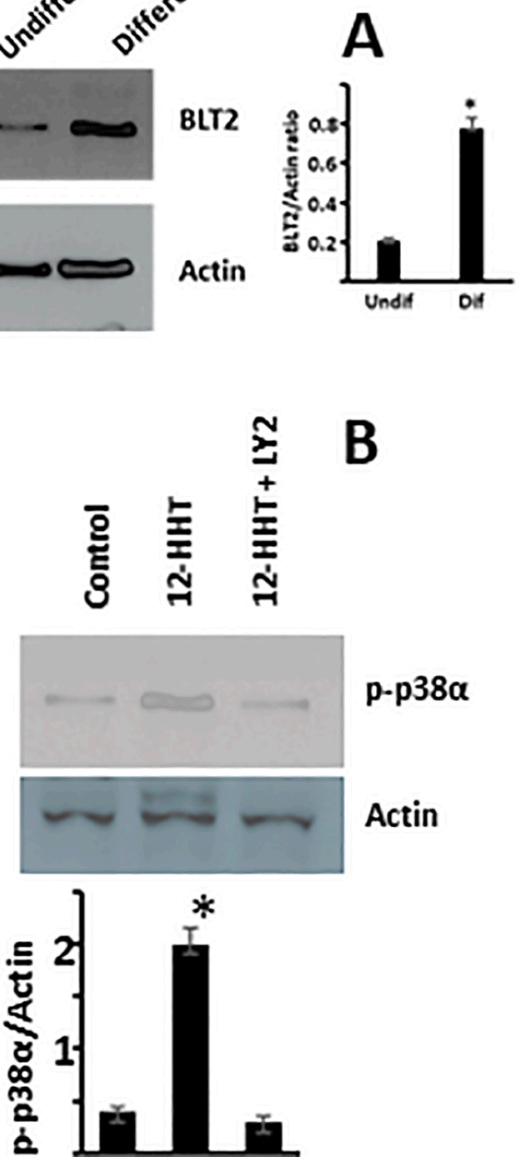

Fig. 3. (A) Western blot determination of BLT2 expression in undifferentiated and differentiated Caco-2 cell cultures. (B) pp38 $\alpha /$ actin and (C) MYPT1/p-MYPT1 and MLC/p-MLC expression in differentiated Caco-2 cell cultures incubated in presence of 12-HHT (100 nM) and LY255283 (LY2, 25 $\mu \mathrm{M})$ for $2 \mathrm{~h}, \mathrm{LY} 255283$ was preincubated 15 min before 12-HHT was added. Bars represent the findings of 3 western blots (media \pm SEM). * $\mathrm{P} \leq 0.05$ vs. undifferentiated Caco-2 cell cultures or control Caco- 2 cell cultures.
Table 2

Cell signalling pathway elements involved in Caco-2 cell growth induced by 12 HHT.

\begin{tabular}{lll}
\hline & $\begin{array}{l}\text { Viable cell number }\left(10^{3} /\right. \\
\left.\mathrm{cm}^{2}\right)\end{array}$ & $\begin{array}{l}\text { DNA synthesis (0.D. } 450 \\
\mathrm{~nm})\end{array}$ \\
\hline Control & $31.2 \pm 2.1$ & $0.32 \pm 0.02$ \\
12-HHT & $63.4 \pm 3.7$ & $0.71 \pm 0.04$ \\
12-HHT + PTX & $41.5 \pm 2.8^{*}$ & $0.43 \pm 0.03^{*}$ \\
12-HHT + & $46.7 \pm 2.6^{*}$ & $0.48 \pm 0.02^{*}$ \\
SB203580 & & \\
12-HHT + PD & $65.2 \pm 2.9$ & $0.68 \pm 0.03$ \\
98,059 & & \\
12-HHT + KT5720 & $66.7 \pm 3.1$ & $0.67 \pm 0.04$ \\
12-HHT + Go9683 & $48,1 \pm 2.3^{*}$ & $0.50 \pm 0.03^{*}$ \\
12-HHT + U73122 & $49.2 \pm 2.5^{*}$ & $0.52 \pm 0.05^{*}$ \\
\hline
\end{tabular}

Non-differentiated Caco-2 cells were incubated with 12-HHT (1000 nM) in presence of toxin pertussis (PTX, $100 \mathrm{ng} / \mathrm{ml}$ ), SB203580 (15 $\mu \mathrm{M})$, PD 98,059 (1 $\mu \mathrm{M})$, KT5720 $(10 \mu \mathrm{M})$, Go9683 $(10 \mu \mathrm{M})$ or U73122 $(10 \mu \mathrm{M})$ for $48 \mathrm{~h}$ and cell growth and DNA synthesis were measured. Results are shown as means \pm SEM from 2 to 3 determinations performed in triplicate. ${ }^{*} \mathrm{P} \leq 0.05$ vs Caco- 2 cells incubated with 12-HHT.

induced a concentration-dependent Caco-2 cell growth (Fig. 1A) and DNA synthesis (Fig. 1B), in the absence of growth factors. In the experimental design FBS was excluded considering that 12-HHT is produced during blood coagulation by activated platelets and it is contented in serum. Considering these initial findings, a concentration of $1 \mu \mathrm{M}$ was chosen to further investigate the mechanism involved in the mitogenic action of 12 -HHT on undifferentiated Caco-2 cells.
Interestingly, we found that the presence of BLT2 antagonist LY255283 [15] reverted the effect of 12 -HHT on Caco-2 cell proliferation/DNA synthesis, whereas LY171883 (a cysteinyl $\mathrm{LT}_{1}$ receptor antagonist) [16], MK 571 (a cysteinyl $\mathrm{LT}_{1}$ receptor antagonist) [17], ketoprofen (a cyclooxygenase inhibitor) [18], SC19220 (a $\mathrm{EP}_{1}$ receptor antagonist) [19] and AH23848 (a EP 4 receptor antagonist) [20] did not modify this mitogenic action induced by 12-HHT (Fig. 2B/C). siRNA BLT2 transfection of Caco-2 cells blocked BLT2 expression (Fig. 2A) and this experimental condition reverted Caco-2 cell growth (Fig. 2B) and DNA synthesis (Fig. 2C) induced by 12-HHT.

To investigate which cell signaling pathways were involved in the 12-HHT effects on Caco-2 cell growth/DNA synthesis, we determined the phosphorylation of AKT1, AKT2, ERK1/2, p38 $\alpha$, CREB and GSK $\beta$ in the absence of FBS and after short incubations (5-15 min) with 12-HHT. Our results showed that 12-HHT (1000 nM) only increased the phosphorylation of $\mathrm{p} 38 \alpha$ (Table 1 ). The effect of 12 -HHT on p38 signaling was also supported by the enhancement of phosphorylated p-38 induced by 12-HHT (Fig. 3B). Furthermore, we observed that undifferentiated Caco-2 cell growth/DNA synthesis induced by 12 -HHT were reverted by a protein $\mathrm{G} \alpha_{1}$ inhibitor (pertussis toxin), by a p38 MAPK inhibitor (SB203580) and by a broad PKC inhibitor (Go8683) but not by a ERK 1/ 2 inhibitor (PD98059), a AMP-PKA inhibitor (KT5720) or by a PLC inhibitor as U73122 (Table 2).

Here, we confirm the BLT2 expression in Caco-2 cell cultures. Interestingly, we observed that BLT2 expression was increased during Caco-2 cell differentiation (Fig. 3A).

Iizuka and co-workers [10] demonstrated that BLT2 deficient mice exhibited enhanced intestinal inflammation and the impairment of 

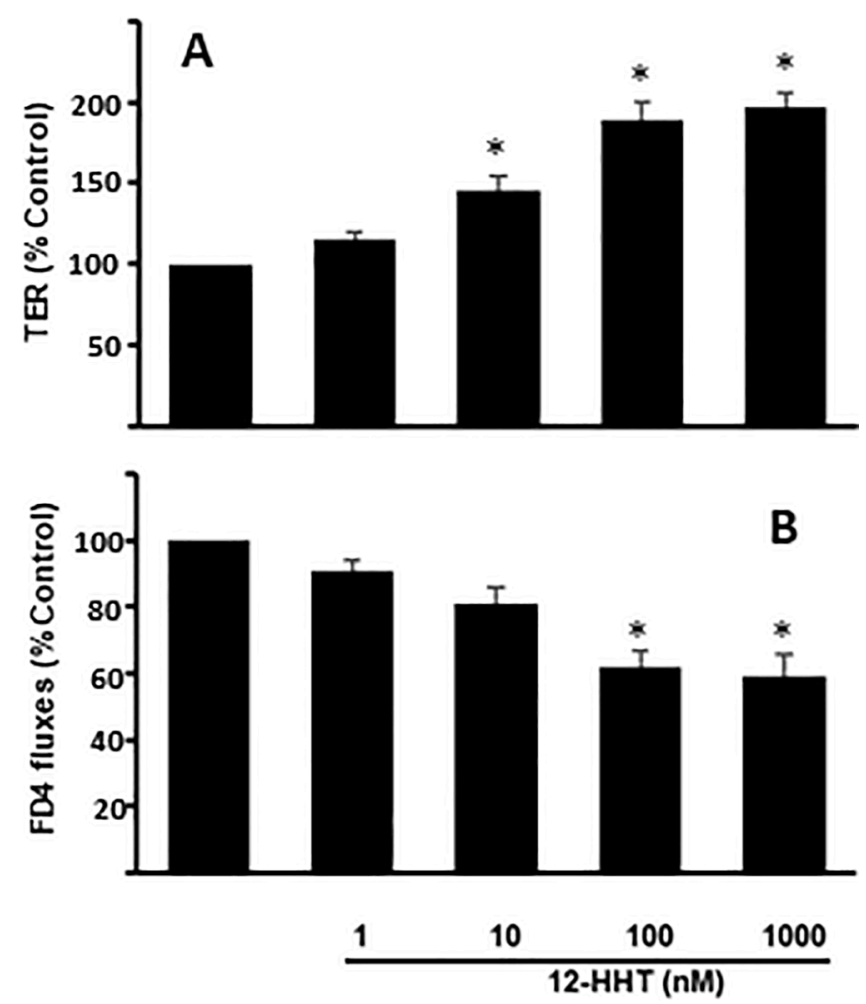

Fig. 4. Effect of 12-HHT on transepithelial resistance (TER) and FD4-fluxes in differentiated Caco- 2 cell cultures. Cell cultures were incubated for $2 \mathrm{~h}$ with 12 HHT (1-1000 nM) in the absence of growth factors (FBS). TER (A), and FD4 fluxes were measured (B). Results are expressed as means \pm SEM of 3 determinations performed in triplicate. * $\mathrm{P} \leq 0.05$ vs. Caco- 2 cell cultured in the absence of 12-HHT.

paracellular permeability suggesting the implication of BLT2 on barrier function.

We observed that 12-HHT induced a significant decrease in FD-4 fluxes and an enhancement in TER basal values of an experimental model of intestinal epithelium constituted by differentiated Caco-2 cultures (Fig. 4A/B).

Next, we explored the role of the receptors involved in these effects of 12-HHT on paracellular permeability through the capacity of various receptor antagonists to prevent the action of these eicosanoids on FD-4 fluxes and TER. The changes in FD-4 fluxes and the TER values induced by 12 -HHT were prevented by BLT2 antagonist LY255283 (Fig. 5A/B) but not by cysteinyl leukotriene receptor antagonists or EP receptor antagonists (data not shown).

Finally, we addressed the participation of several signaling pathways in this improve of PP by 12-HHT. The results revealed that the decrease in FD-4 fluxes and the impairment of TER induced by 12-HHT (Fig. 5A/ B) were prevented by SB 203580, a p38 inhibitor [21]; Gö6983, a panprotein kinase (PK) C inhibitor [22] and Y27632, a MYPT1 inhibitor [23]. Considering that 12-HHT increased the phosphorylation of myosin light chain (MLC) and that this effect was also reverted by BLT2 antagonist (Fig. 3C), we can consider the role of the pathway 12-HHTBLT2-p38-PKC-MLC in the improvement of PP induced by 12-HHT. Western blotting of phosphorylated myosin phosphatase target subunit 1 (MYPT1) revealed that 12-HHT interaction with BLT2 stimulated phosphorylation of this key element of MLC phosphorylation (Fig. 3C).

Previously, we observed that some pro-inflammatory eicosanoids from arachidonic acid such as $\mathrm{PGE}_{2}$ disrupt barrier function [24]. Interestingly, we can observe that 12-HHT (100 nM) was able to revert the paracellular permeability disruption induced by $\mathrm{PGE}_{2}(10 \mathrm{nM})$ (Fig. 6), and that this effect was blocked by a BLT2 antagonist and by siRNA BLT2 treatment.
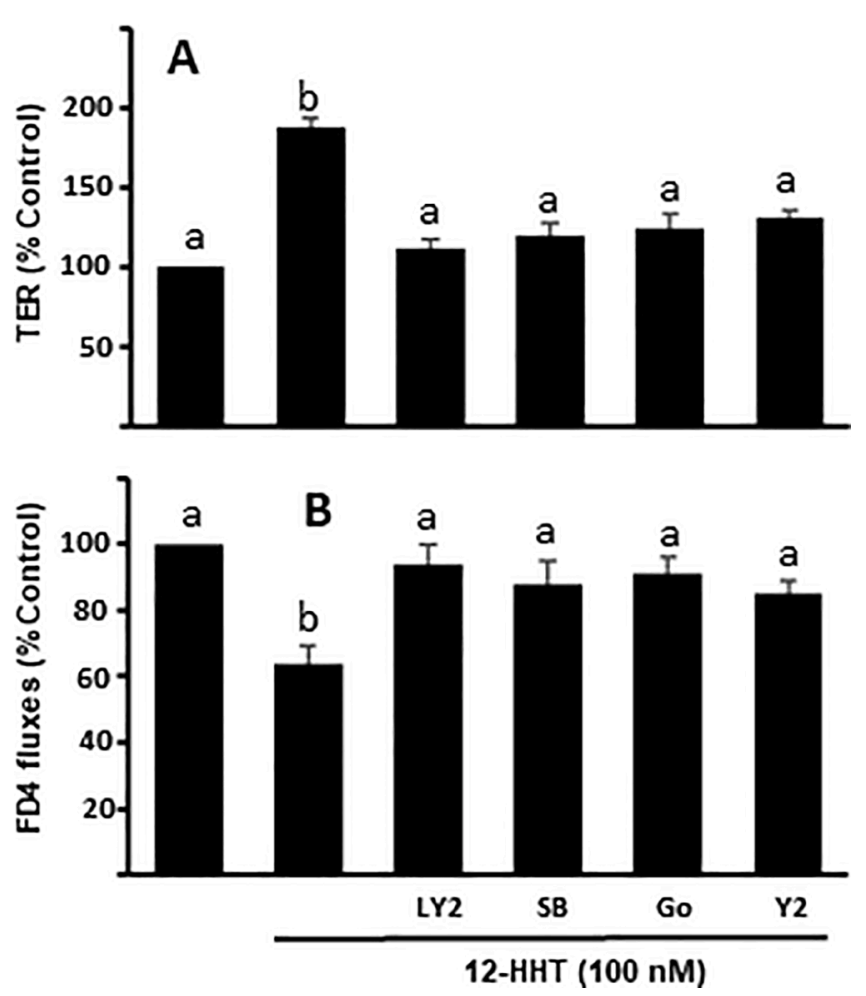

Fig. 5. Cell signaling pathways involved in paracellular permeability changes induced by 12 -HHT in differentiated Caco-2 cultures. Cells were incubated for $2 \mathrm{~h}$ in presence of LY255283 (LY2, $25 \mu \mathrm{M}$ ), SB203580 (SB, $15 \mu \mathrm{M}$ ), Go9683 (Go, $10 \mu \mathrm{M})$ or Y27632 (Y2, $10 \mu \mathrm{g})$ and 12 HHT (100 nM). TER (A) and FD-4 fluxes (B) were measured. Results are expressed as means \pm SEM of 3-5 determinations performed in triplicate. Values that do not share a common letter $(a-c)$ were significantly different $(\mathrm{p}<0.05)$.
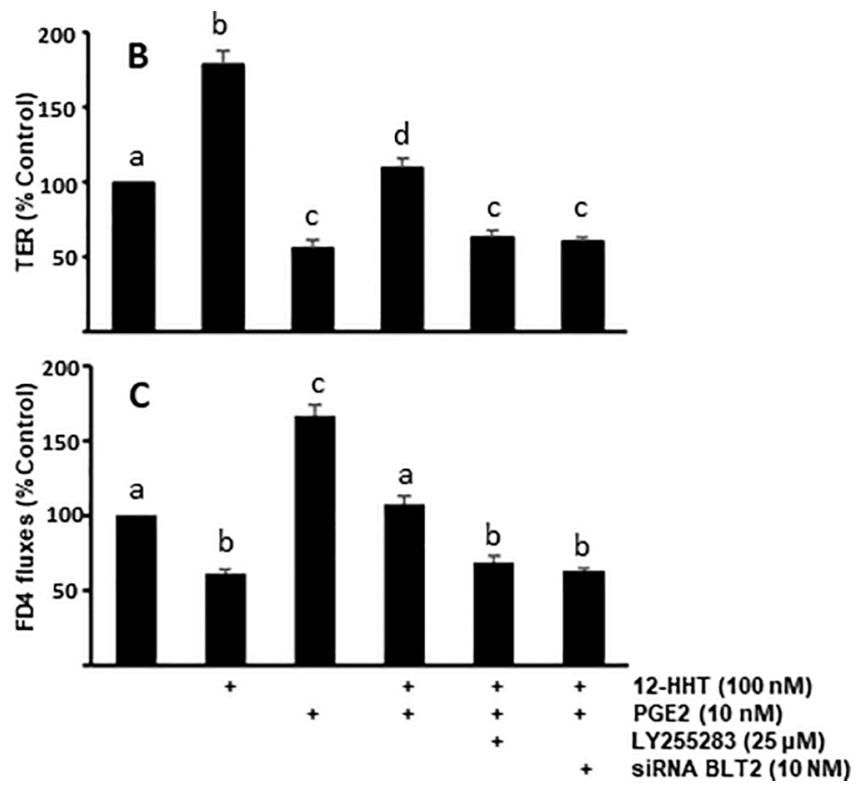

Fig. 6. Effects of 12-HHT on the disruption of paracellular permeability induced by $\mathrm{PGE}_{2}$. Differentiated Caco- 2 cell cultures were incubated for $2 \mathrm{~h}$ with PGE 2 (10 nM) in the presence of 12-HHT (100 nM) and LY255283 (LY2, $25 \mu \mathrm{M})$ or cultures transfected with siRNA BLT2 (10 nM). TER (A), and FD4 fluxes were measured (B). Values that do not share a common letter $(a-c)$ were significantly different $(\mathrm{p}<0.05)$. 


\section{Discussion}

In an indomethacin-induced Crohn's disease model, compared with wild-type mice, BLT2-deficient mice had less efficiency in the healing of Crohn's disease-like intestinal lesions [25]. This was explained by the reduced epithelial cell proliferation during the healing process in BLT2 deficient animals. In this way, CAY10583, a specific BLT2 agonist, accelerated wound repair by stimulating cell proliferation instead of migration. Thus, this recent study suggests that BLT2 possibly plays an important role in the healing of intestinal lesions by accelerating epithelial cell proliferation. Although there is evidence supporting the importance of BLT2 ligands on intestinal epithelial cell growth, there are not reports that directly demonstrated 12-HHT effects. Here, we reported at the first time that 12-HHT through BLT2 interaction has a mitogenic action on human intestinal epithelial at concentrations reached in the intestinal mucosa [26]. Furthermore, our findings shown that other eicosanoid receptors such as cysteinyl leukotriene receptors and $\mathrm{EP}_{1} / \mathrm{EP}_{4}$ receptors, that were involved in Caco-2 cell growth induced by FBS $[12,27]$, are not involved in these events. Moreover, we observed that the human intestinal epithelial Caco-2 cell growth induced by 12-HHT was consequence of the activation of $\mathrm{G}$ protein, $\mathrm{p} 38$ MAP kinase and PKC. These cellular signaling events were also activated by CAY10583, a BLT2 agonist, that stimulated murine colon epithelial cell growth [25]. It is interesting to note that Matsumoto and co-workers only reported a CAY10583 mitogenic effect in presence of 5\% bovine serum whereas this BLT2 agonist did not have any effects on colon cell growth in absence of serum [25]. In contrast, our findings demonstrated a mitogenic action by 12 -HHT in absence of serum or growth factors. This role of p38 in 12-HHT mitogenic action was also recently described by Liu and co-workers [28] using a bronchial epithelial cell line. It is interesting to consider that some eicosanoids such as 12-HETE also activated this cell signaling $[12,27,29]$. Considering that 12 -HHT has been proposed as a wound healing promoter on skin [30,31], we can suppose that this mitogenic acid of 12-HHT on intestinal epithelial cells may be involved in the intestinal epithelium regeneration/repair processes as was previously suggested by other eicosanoids such as prostaglandins/leukotrienes and HETEs [11]. It is important to note that these eicosanoids are also synthesized during inflammation and are involved in the disruption of intestinal barrier function. However, our findings appoint that 12-HHT has a notable capacity to improve PP.

It has been demonstrated that TER and the flux assays are suitable in vitro models to determine the PP and we previously used this experimental design to study the effects of some eicosanoids such as $\mathrm{PGE}_{2}$ [24], and 5-HETE and $\mathrm{LTD}_{4}$ [31] on barrier function. Then, we shown that actin filaments are involved in the integrity of the barrier function of tight junctions, and that disruption of the assembly of F-actin causes a reduction in TER and the enhancement of dextran fluxes by the above mentioned pro-inflammatory eicosanoids [24,32]. Here, we demonstrated that 12-HHT has a contrary action on barrier function. Thus, we observed that 12-HHT was able to improve basal PP of Caco-2 cell cultures by BLT2-p38-PKC-MLC pathway in a similar form as recent studies performed using other cellular models such as normal human epidermal keratinocyte cultures [33]. Interestingly, these effects were significant at $10 \mathrm{nM} 12-\mathrm{HHT}$, findings that suggest a more sensitivity from 12-HHT by differentiated Caco-2 cultures, perhaps as consequence of a higher BLT2 expression in differentiated Caco- 2 cultures than undifferentiated Caco2 cultures as we above mentioned.

Okuno and Yokomizo [6] suggested that 12-HHT BLT2 axis contributes to the control of epithelial barrier function in the small intestine. Here, we demonstrated these effects in experimental epithelium constituted by differentiated Caco- 2 cells. We observed the enhancement of BLT2 expression during Caco-2 differentiation. Furthermore, this fact could be related with the improvement of differentiated Caco-2 culture PP by 12-HHT at lower concentrations than those that induced undifferentiated Caco- 2 cell growth. Moreover, we also appointed the role of protein $\mathrm{G}$ inhibited by pertussis toxin, p38 and PKC in the cell signaling involved in the improve of PP induced by 12-HHT through the control of MLC phosphorylation and the subsequent F-actin assembly [34]. Increased activity of MLC kinase and/or decreased activity of MLC phosphatases were shown to enhance the range of MLC phosphorylation. MYPT1 is one of the components of MLC phosphatases (MLCP). Rho-associated protein kinase (ROCK) is the key element involved in the MYPT1 phosphorylation [35]. The phosphorylation of MYPT1 inhibits the phosphatase activity of MLCP. Our results demonstrated that 12HHT-BLT2 interaction enhances MYPT1 phosphorylation and consequently MLC phosphorylation. Interestingly, the Rho kinase inhibitor Y27632 was also able to revert the improvement of barrier function induced by 12-HHT, findings that suggest the role of 12-HHT-BLT2Rho/Rock/MLCP on intestinal epithelial PP. To the best of our knowledge, this is the first in vitro report to show a molecular mechanism by which 12-HHT-BLT2 could be involved in the maintain of intestinal barrier function.

Obviously, other tight junction elements can be also involved in this 12-HHT action. Thus, 12-HHT BLT2 p38 pathway also regulated claudin expression/distribution in skin [36]. Considering that claudins and ZO-1 and occludins are key elements involved in the intestinal PP, a more profound analysis of the effects of 12-HHT on tight junction elements should be performed in next studies.

Interestingly, our results demonstrated that 12 -HHT was also capable to revert the disruption of PP induced by pro-inflammatory eicosanoids such as $\mathrm{PGE}_{2}$ through BLT2 interaction. Thus, 12-HHT might be involved in the control of epithelium regeneration and the conservation of the barrier function and consequently we can consider to 12-HHT as an important element of the arachidonic acid cascade involved in the control of intestinal epithelium repair/regeneration homeostasis.

In conclusion, 12-HHT is an eicosanoid that can be involved in intestinal epithelial cell growth and consequently in the epithelium regeneration/repair processes in a similar form as other eicosanoids. Interestingly, as a BLT2 ligand, 12-HHT did not disrupt barrier function, at contrary, presented an interesting, improved action on PP. These effects appoint that 12-HHT/BLT2 axis may be a suitable strategy for treating barrier-disrupted intestinal processes.

\section{Declaration of Competing Interest}

The authors declare that they have no known competing financial interests or personal relationships that could have appeared to influence the work reported in this paper.

\section{Acknowledgments}

Cytometry analyses were performed at the Serveis Cientific-Tècnics of the University of Barcelona. Some of the results presented here appeared in Carolina E. Storniolo doctoral thesis. We agree the suggestions offered by Dr. M.T. Mitjavila.

\section{References}

[1] M. Hamberg, J. Svensson, B. Samuelsson, Prostaglandin endoperoxides. A new concept concerning the mode of action and release of prostaglandins, Proc. Natl. Acad. Sci. USA 71 (10) (1974) 3824-3828, https://doi.org/10.1073/ pnas.71.10.3824.

[2] R.F. Shen, H.H. Tai, N. Harada, T. Harayama, H. Shindou, J.-D. Li, M. Murakami, $\mathrm{S}$. Hoka, T. Yokomizo, Leukotriene $\mathrm{B}_{4}$ receptor type 2 protects against pneumolysin-dependent acute lung injury, J. Biol. Chem. 261 (1986) 11592-11599, https://doi.org/10.1038/srep34560.

[3] Y. Liu, K. Yoden, R.F. Shen, H.H. Tai, 12-L-hydroxy-5,8,10-heptadecatrienoic acid (HHT) is an excellent substrate for NAD+-dependent 15-hydroxyprostaglandin dehydrogenase, Biochem. Biophys. Res. Commun. 129 (1985) 268-274, https:// doi.org/10.3390/medsci7040065.

[4] T. Okuno, Y. Iizuka, H. Okazaki, T. Yokomizo, R. Taguchi, T. Shimizu, 12(S)hydroxyheptadeca-5Z, 8E, 10E-trienoic acid is a natural ligand for leukotriene B4 receptor 2, J. Exp. Med. 205 (2008) 759-766, https://doi.org/10.1084/ jem.20072329.

[5] Y. Iizuka, T. Yokomizo, K. Terawaki, M. Komine, K. Tamaki, T. Shimizu, Characterization of a mouse second leukotriene B4 receptor, mBLT2: BLT2- 
dependent ERK activation and cell migration of primary mouse keratinocytes, J. Biol. Chem. 280 (26) (2005) 24816-24823, https://doi.org/10.1074/jbc. M413257200.

[6] T. Okuno, Y. Yokomizo, Biological functions of 12(S)-hydroxyheptadeca5Z,8E,10E-trienoic acid as a ligand of leukotriene B(4) receptor 2, Inflam. Reagen. 38 (2018) 29.

[7] K. Punnonen, P. Uotila, E. Mantyla, The effects of aspirin and OKY-1581 on the metabolism of exogenous arachidonic acid in rat alveolar macrophages, Res. Commun. Chem. Pathol. Pharmacol. 44 (1984) 367-374.

[8] D. Peus, R.A. Vasa, A. Beyerle, A. Meves, C. Krautmacher, M.R. Pittelkow, UVB activates ERK1/2 and p38 signaling pathways via reactive oxygen species in cultured keratinocytes, J. Invest. Dermatol. 112 (5) (1999) 751-756, https://doi. org/10.1046/j.1523-1747.1999.00584.x.

[9] A. Comba, D.M. Maestri, M.A. Berra, C. Garcia, U.N. Das, A.R. Eynard, M. E. Pasqualini, Effect of $\omega-3$ and $\omega-9$ fatty acid rich oils on lipoxygenases and cyclooxygenases enzymes and on the growth of a mammary adenocarcinoma model, Lipids Health Dis. 9 (1) (2010) 112, https://doi.org/10.1186/1476-511X-9112.

[10] Y. Iizuka, T. Okuno, K. Saeki, H. Uozaki, S. Okada, T. Misaka, T. Sato, H. Toh, M. Fukayama, N. Takeda, Y. Kita, T. Shimizu, M. Nakamura, T. Yokomizo, Protective role of the leukotriene B4 receptor BLT2 in murine inflammatory colitis, FASEB J. 24 (12) (2010) 4678-4690, https://doi.org/10.1096/fj.10-165050.

[11] R. Ferrer, J.J. Moreno, Role of eicosanoids on intestinal epithelial homeostasis, Biochem. Pharmacol. 80 (2010) 431-438, https://doi.org/10.1016/j. bcp.2010.04.033.

[12] M. Cabral, R. Martin-Venegas, J.J. Moreno, Role of arachidonic acid metabolites on the control of non-differentiated intestinal epithelial cell growth, Int. J. Biochem. Cell. Biol. 45 (2013) 1620-1628, https://doi.org/10.1016/j.biocel.2013.05.009.

[13] M. Cabral, R. Martín-Venegas, J.J. Moreno, Differential cell growth/apoptosis behavior of 13-hydroxyoctadecadienoic acid enantiomers in a colorectal cancer cell line, Am. J. Physiol. Gastrointest. Liver Physiol. 307 (2014) G664-G671, https://doi.org/10.1152/ajpgi.00064.2014.

[14] R. Martién-Venegas, S. Roig-Peérez, R. Ferrer, J.J. Moreno, Arachidonic acid cascade and epithelial barrier function during Caco-2 cell differentiation, J. Lipid Res. 47 (7) (2006) 1416-1423, https://doi.org/10.1194/jlr.M500564-JLR200.

[15] T. Yokomizo, K. Kato, K. Terawaki, T. Izumi, T. Shimizu, A second leukotriene B receptor, $\mathrm{BLT}_{2}$ : a new therapeutic target in inflammation and immunological diseases, J. Exp. Med. 192 (2000) 421-431, https://doi.org/10.1084/ jem.192.3.421.

[16] J.H. Fleisch, L.E. Rinkema, K.D. Haisch, D. Swanson-Bean, T. Goodson, P.P. Ho, W S. Marshall, LY171883, 1-less than 2-hydroxy-3-propyl-4-less than 4-(1H-tetrazol5 -yl) butoxy greater than phenyl greater than ethanone, an orally active leukotrieneD4 antagonist, J. Pharmacol. Exp. Ther. (1985) 233148-233157.

[17] V. Martin, N. Sawyer, R. Stocco, D. Unett, M.R. Lerner, M. Abramovitz, C.D. Funk, Molecular cloning and functional characterization of murine cysteinyl-leukotriene 1(CysLT(1)) receptors, Biochem. Pharmacol. 62 (2001) 1193-1200, https://doi. org/10.1016/s0006-2952(01)00774-2.

[18] T. Sánchez, J.J. Moreno, Ketoprofen S (+) enantiomer inhibits prostaglandin production and cell growth in 3T6 fibroblast cultures, Eur. J. Pharmacol. 370 (1) (1999) 63-67, https://doi.org/10.1016/S0014-2999(99)00108-9.

[19] C.D. Funk, L. Furci, G.A. FitzGerald, R. Grygorczyk, C. Rochette, M.A. Bayne, M. Abramovitz, M. Adam, K.M. Metters, Cloning and expression of a cDNA for the human prostaglandin E receptor EP1 subtype, J. Biol. Chem. 268 (35) (1993) 26767-26772.

[20] N. Nishigaki, M. Negishi, A. Honda, Y. Sugimoto, T. Namba, S. Narumiya, A. Ichikawa, Identification of prostaglandin $\mathrm{E}$ receptor " $\mathrm{EP}_{2}$ " cloned from mastocytoma cells as $\mathrm{EP}_{4}$ subtype-, FEBS Lett. 364 (1995) 339-341, https://doi. org/10.1016/0014-5793(95)00421-5.

[21] A. Cuenda, J. Rouse, Y.N. Doza, R. Meier, P. Cohen, T.F. Gallagher, P.R. Young, J. C. Lee, SB 203580 is a specific inhibitor of a MAP kinase homologue which is stimulated by cellular stresses and interleukin-1, FEBS Lett. 364 (1995) 229-233, https://doi.org/10.1016/0014-5793(95)00357-f.
[22] B.H. Shah, J.A. Olivares-Reyes, K.J. Catt, The protein kinase C inhibitor Go6976 [12-(2-cyanoethyl)-6,7,12,13-tetrahydro-13-methyl-5-oxo-5H-indolo(2,3-a) pyrrolo(3,4-c)-carbazole] potentiates agonist-induced mitogen-activated protein kinase activation through tyrosine phosphorylation of the epidermal growth factor receptor, Mol. Pharmacol. 67 (2005) 184-194, https://doi.org/10.1124/ mol.104.003533.

[23] M. Uehata, T. Ishizaki, H. Satoh, T. Ono, T. Kawahara, T. Morishita, H. Tamakawa, K. Yamagami, J. Inui, M. Maekawa, S. Narumiya, Calcium sensitization of smooth muscle mediated by a Rho-associated protein kinase in hypertension, Nature 389 (6654) (1997) 990-994, https://doi.org/10.1038/40187.

[24] M.J. Rodríguez-Lagunas, R. Martín-Venegas, J.J. Moreno, R. Ferrer, PGE 2 promotes $\mathrm{Ca}^{2+}$-mediated epithelial barrier disruption through $\mathrm{EP}_{1}$ and $\mathrm{EP}_{4}$ receptors in Caco2 cell monolayers, Am. J. Physiol. Cell. Physiol. 299 (2010) C324-C334, https:// doi.org/10.1152/ajpcell.00397.2009.

[25] Y. Matsumoto, Y. Matsuya, K. Nagai, K. Amagase, K. Saeki, K. Matsumoto, T. Yokomizo, S. Kato, Leukotriene B(4) receptor type 2 accelerates the healing of intestinal lesions by promoting epithelial cell proliferation, J. Pharmacol. Exp. Ther. 373 (2020) 1-9, https://doi.org/10.1124/jpet.119.263145.

[26] F. J. Zijlstra, A. P. van Dijk, I. M. Garrelds, R. J. Ouwendijk, J. H. Wilson, Species differences in the pattern of eicosanoids produced by inflamed and non-inflamed tissue, Agents Actions Spec No (1992) C73-75.

[27] M. Cabral, R. Martín-Venegas, J.J. Moreno, Leukotriene D4-induced Caco-2 cell proliferation is mediated by prostaglandin $\mathrm{E}_{2}$ synthesis, Physiol. Rep. 3 (2015), e12417, https://doi.org/10.14814/phy2.12417.

[28] M. Liu, J. Shen, H. Yuan, F. Chen, H. Song, H. Qin, Y. Li, J. Xu, Q. Ye, S. Li, K. Saeki, T. Yokomizo, Leukotriene B4 receptor 2 regulates the proliferation, migration, and barrier integrity of bronchial epithelial cells, J. Cell. Physiol. 233 (8) (2018) 6117-6124, https://doi.org/10.1002/jcp.26455.

[29] D. Nieves, J.J. Moreno, Enantioselective effect of 12(S)-hydroxyeicosatetraenoic acidon 3 T6 fibroblast growth through ERK $1 / 2$ and p38 MAPK pathways and cyclin D1 activation, Biochem. Pharmacol. 76 (5) (2008) 654-661, https://doi.org/ 10.1016/j.bcp.2008.06.013.

[30] A. Leguina-Ruzzi, R. Ortiz Diban, V. Velarde, The 12-HHT/BLT2/NO axis is associated to the wound healing and skin condition in different glycaemic states, Med. Sci. (Basel) 7 (2019) 65, https://doi.org/10.3390/medsci7040065.

[31] V. Hernandez-Olmos, J. Heering, V. Planz, T. Liu, A. Kaps, R. Rajkumar, M. Gramzow, A. Kaiser, M. Schubert-Zsilavecz, M.J. Parnham, M. Windbergs, D. Steinhilber, E. Proschak, First structure-activity relationship study of potent BLT2 agonists as potential wound-healing promoters, J. Med. Chem. 63 (20) (2020) 11548-11572, https://doi.org/10.1021/acs.jmedchem.0c00588.

[32] M.J. Rodríguez-Lagunas, C.E. Storniolo, R. Ferrer, J.J. Moreno, 5Hydroxyeicosatetraenoic acid and leukotriene $\mathrm{D}_{4}$ increase intestinal epithelial paracellular permeability, Int. J. Biochem. Cell. Biol. 45 (7) (2013) 1318-1326, https://doi.org/10.1016/j.biocel.2013.04.005.

[33] T. Chiba, T. Nakahara, A. Hashimoto-Hachiya, T. Yokomizo, H. Uchi, M. Furue, The leukotriene $\mathrm{B}_{4}$ receptor BLT2 protects barrier function via actin polymerization with phosphorylation of myosin phosphatase target subunit 1 in human keratinocytes, Exp. Dermatol. 25 (2016) 532-536, https://doi.org/10.1111/ exd.12976.

[34] M. Shigematsu, T. Koga, A. Ishimori, K. Saeki, Y. Ishii, Y. Taketomi, M. Ohba, A. T. Sokabe, T. Fukumi-Tominaga, S. Yonemura, A. Mizuno, M. Tominaga, The TRPV4 channel contributes to intercellular junction formation in keratinocytes, J. Biol. Chem. 285 (24) (2010) 18749-18758, https://doi.org/10.1074/jbc. M110.103606.

[35] T. Matsuoka, M. Yashiro, Rho/ROCK signaling in motility and metastasis of gastric cancer, World J. Gastroenterol. 20 (2014) 13756-13766, https://doi.org/10.3748/ wjg.v20.i38.13756.

[36] Y. Ishii, K. Saeki, M. Liu, F. Sasaki, T. Koga, K. Kitajima, C. Meno, T. Okuno, Y. Yokomizo, Leukotriene B4 receptor type 2 (BLT2) enhances skin barrier function by regulating tight junction proteins, FASEB J. 30 (2016) 930-947, https://doi. org/10.1096/fj.15-279653. 